Dikirim: 13 Oktober 2015 Diterbitkan: 1 September 2016

\section{Peran kepala puskesmas SKM dan non SKM dalam meningkatkan kemampuan manajerial puskesmas di kabupaten Oku Timur}

\author{
Role of the head of public health centers from public health \\ graduates and others on improving managerial skills in East Oku
}

Aulawi Aulawi ${ }^{1}$, Riris Andono Ahmad ${ }^{2}$, Mubasysyir Hasanbasri ${ }^{2}$

\begin{abstract}
Purpose: This study aimed to understand how public health and non-public health backgrounds affect management skill of primary health care heads, based on ten managerial roles. Methods: This study was a descriptive study with case-series method, using qualitative methods supported by quantitative data. Eight people were recruited as respondents. They consisted of 4 people that were primary healthcare heads with public health background and 4 people that were primary healthcare heads with non-public health background. Respondents were recruited by purposive sampling. Data collection was performed using in-depth interviews and questionnaire. Results: Primary healthcare head with public health background owned more work experience than those with non-public health background. Period of employment in primary health care had an influence on managerial capabilities. There were no significant differences of period of employment in primary health care head positions among the longest with the least to the managerial capabilities. Primary health care heads who had been trained with PIM IV training and other structural positions were known to have better management capabilities, especially compared to the leadership role of those who had not been trained. Conclusion: There was no significant difference in managerial capacity between primary health care heads with public health and those with non-public health background.
\end{abstract}

Keywords: role; head of health center; managerial capability

\footnotetext{
${ }^{1}$ Departemen Kebijakan dan Manajemen Kesehatan, Fakultas Kedokteran, Universitas Gadjah Mada 


\section{PENDAHULUAN}

Puskesmas bertanggung jawab terhadap upaya kesehatan untuk jenjang tingkat pertama (1). Data dinas kesehatan menunjukkan terdapat 22 unit puskesmas di kabupaten OKU Timur yang terdiri dari 11 unit perawatan dan 11 unit non perawatan (2). kabupaten OKU Timur termasuk kabupaten yang telah menerapkan status puskesmas menjadi unit pelaksana teknis daerah (UPTD) puskesmas. Puskesmas yang dipimpin oleh SKM berjumlah 15 puskesmas dan 7 puskesmas dipimpin oleh non SKM.

Kebijakan memberi peluang SKM menjadi kepala puskesmas di kabupaten OKU Timur belum disertasi dengan evaluasi menyeluruh terhadap kinerja yang dihasilkan, baik kepala puskesmas SKM dan non SKM untuk melihat potensi setiap pimpinan. Mintzberg menjelaskan salah satu yang dapat mengetahui kemampuan manajerial adalah dengan menggunakan 10 peran manajerial. Kemampuan manajerial yang baik memengaruhi kinerja dalam suatu lingkungan organisasi (3). Gibson menjelaskan beberapa faktor yang memengaruhi penampilan kerja atau kinerja karyawan meliputi pendidikan, jenis kelamin dan masa kerja (4). Sutermeister menyatakan beberapa faktor yang dapat memengaruhi kinerja karyawan adalah pengalaman dan pelatihan (5). Penelitian ini bertujuan untuk mengetahui kemampuan manajerial kepala puskesmas SKM dan non SKM berdasarkan 10 peran manajerial.

\section{METODE}

Penelitian kualitatif yang didukung dengan data kuantitatif, dengan rancangan studi kasus. Sampel penelitian sebanyak 8 orang terdiri dari 4 orang kepala puskesmas SKM dan 4 orang kepala puskesmas non
SKM. Staf yang menjadi informan untuk dimintai pendapat tentang kemampuan manajerial pimpinan sebanyak 40 orang dan 1 orang pejabat dinas kesehatan. Pengambilan sampel dilakukan secara purposive sampling. Lokasi penelitian di puskesmas kabupaten OKU Timur, Sumatera Selatan. Instrumen adalah panduan wawancara mendalam. Pengumpulan data diperoleh melalui wawancara mendalam dan kuesioner menggunakan skala likert.

\section{HASIL}

Peran antar pribadi. Kegiatan sebagai tokoh utama lebih banyak dilakukan oleh kepala puskesmas SKM. Hal tersebut disebabkan karena kepala puskesmas SKM tidak mempunyai peran ganda sebagai pemegang jabatan struktural dan fungsional tetapi berperan sebagai pemegang jabatan struktural. Sebagai pemimpin, kepala puskesmas SKM lebih menekankan kepada adanya tugas, pokok dan fungsi (tupoksi) yang jelas dan tidak membuat jarak dengan staf. Hal tersebut berbeda dengan kepala puskesmas non SKM yang lebih menekankan kepada ketegasan sanksi atau denda.

Sebagai penghubung, kepala puskesmas SKM mempunyai kemudahan dalam menjalin komunikasi antar lintas sektor, karena kebanyakan kepala puskesmas SKM mempunyai sifat terbuka dan tidak menjaga jarak hubungan dengan lintas sektor. Peran informasi. Sebagai pengawas, kepala puskesmas SKM mempunyai waktu lebih banyak untuk melakukan pengawasan internal dan eksternal puskesmas, seperti supervisi, monitoring dan evaluasi ke jejaring puskesmas. Penyebar informasi, semua kepala puskesmas menjalankan peran sebagai penyebar informasi.

Tabel 1. Perbedaan kemampuan manajerial kepala puskesmas berdasarkan peran antar pribadi

\begin{tabular}{|c|c|c|}
\hline Peran Antar Pribadi & Kepala Puskesmas SKM & $\begin{array}{l}\text { Kepala Puskesmas } \\
\text { Non SKM }\end{array}$ \\
\hline \multirow[t]{3}{*}{ Tokoh utama } & Lebih fokus dalam melaksanakan setiap kegiatan & Mempunyai tanggung jawab ganda antara \\
\hline & baik dalam atau luar gedung & pasien dan urusan kantor \\
\hline & Banyak melakukan kegiatan di luar gedung & $\begin{array}{l}\text { Lebih sedikit melakukan kegiatan di luar } \\
\text { gedung }\end{array}$ \\
\hline \multirow[t]{4}{*}{ Pemimpin } & $\begin{array}{l}\text { Kepemimpinan lebih menekankan pada tupoksi } \\
\text { yang jelas }\end{array}$ & $\begin{array}{l}\text { Kepemimpinan lebih menekankan pada sanksi } \\
\text { atau denda }\end{array}$ \\
\hline & $\begin{array}{l}\text { Tidak membuat jarak dengan staf sehingga lebih } \\
\text { terbuka }\end{array}$ & $\begin{array}{l}\text { Menjaga jarak dengan staf sehingga terkesan } \\
\text { kaku dalam hubungan kerja }\end{array}$ \\
\hline & $\begin{array}{l}\text { Menjadikan staf sebagai tim kerja, bukan } \\
\text { dianggap sebagai bawahan }\end{array}$ & Sulit menjalin kemitraan dengan lintas sektor \\
\hline & $\begin{array}{l}\text { Lebih mudah menjalin kemitraan dengan lintas } \\
\text { sektor }\end{array}$ & \\
\hline Penghubung & $\begin{array}{l}\text { Mempunyai kemudahan dalam berkomunikasi } \\
\text { dengan lintas sektor }\end{array}$ & $\begin{array}{l}\text { Tidak mudah menjalin komunikasi dengan } \\
\text { lintas sektor }\end{array}$ \\
\hline
\end{tabular}


Tabel 2. Perbedaan kemampuan manajerial kepala puskesmas berdasarkan peran informasi

\section{Peran Antar Pribadi}

Pengawasan

Penyebar informasi

Juru bicara
Kepala Puskesmas SKM

Lebih fokus dalam melaksanakan setiap

kegiatan baik dalam atau luar gedung

Mempunyai waktu lebih banyak untuk melakukan pengawasan di internal dan eksternal puskesmas seperti supervisi, monitoring dan evaluasi ke jejarang puskesmas.

Mengumpulkan informasi pada jam kerja lebih leluasa dilakukan, seperti browsing internet, melakukan up date data puskesmas dan sebagianya.
Kepala Puskesmas

Non SKM

Mempunyai tanggung jawab ganda antara pasien dan urusan kantor

Tidak memiliki waktu yang banyak dalam melaksanakan pengawasan terutama di eksternal puskesmas karena mengingat peran ganda antara mempunyai tanggung jawab dengan pasien dan melakukan tugas harian kantor

Mengumpulkan informasi harus menunggu waktu senggang, setelah selesai melaksanakan tanggung jawab terhadap pasien.

peran juru bicara biasanya dilakukan pada Peran juru bicara dalam kegiatan luar kegiatan luar gedung, seperti penyuluhan, gedung, karena waktu yang dimilikinya sosialisasi program, dan pertemuan lintas terbatas sehingga hanya melakukan sektor, sehingga waktu untuk melakukan kegiatan yang dianggapnya penting saja kegiatan tersebut lebih memungkinkan atau kegiatan yang dirasakan perlu untuk mengingat tidak adanya peran ganda dihadiri. dalam kepemimpinannya
Peran pemutus. Wirausahawan, sebagian besar kepala puskesmas dalam mencari institusi untuk mengidentifikasi peluang guna perubahan organisasi belum ada. Namun, hanya bersifat struktural, dari puskesmas diajukan ke dinas kesehatan yang merupakan kebutuhan rutinitas puskesmas.

Penanganan gangguan, dalam penyelesaian masalah atau menghentikan kelakuaan buruk staf, kepala puskesmas SKM lebih cenderung melalui kekeluargaan sedangkan non SKM lebih menerapkan aturan dan sanksi yang berlaku .

Pengalokasian sumber daya, kepala puskesmas SKM terkesan kurang tegas dalam memutuskan penempatan tugas pegawai, sedangkan kepala puskesmas non SKM lebih tegas dalam memutuskan penempatan tugas pegawai. Perunding, kepala puskesmas SKM lebih bersifat kompromi dalam menyelesaikan masalah, sedangkan kepala puskesmas non SKM lebih mengacu pada aturan yang ada sehingga terkesan kaku.

Tabel 3. Perbedaan kemampuan manajerial kepala puskesmas berdasarkan peran pemutus

\begin{tabular}{lll}
\hline \multicolumn{1}{c}{ Peran Pemutus } & \multicolumn{1}{c}{ Kepala Puskesmas SKM } & \multicolumn{1}{c}{ Kepala Puskesmas } \\
Non SKM
\end{tabular}

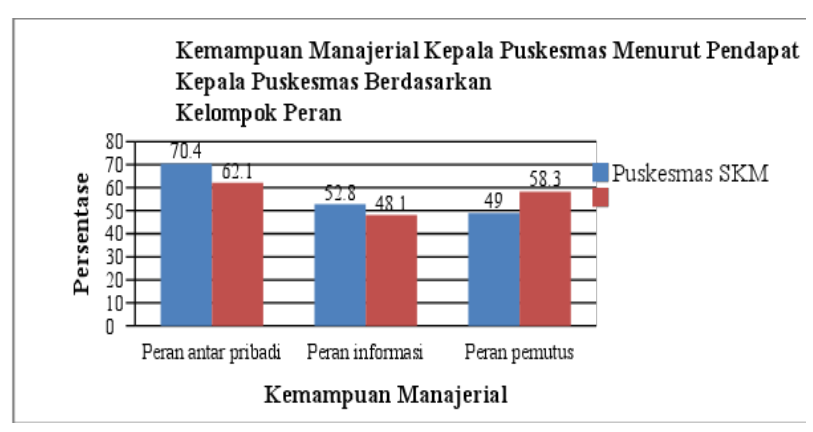

Gambar 1. Kemampuan manajerial kepala puskesmas menurut pendapat kepala puskesmas berdasarkan kelompok peran
Untuk mendukung hasil wawancara dari 3 peran utama kemampuan manajerial tersebut dilakukan penilaian melalui kuesioner berdasarkan pendapat kepala dan staf puskesmas. Gambar 1 menjelaskan kemampuan manajerial menurut pendapat kepala puskesmas, diperoleh hasil skor tertinggi kepala puskemas SKM $(70,4 \%)$ dan non SKM $(62,1 \%)$ terdapat pada kelompok peran antar pribadi. 


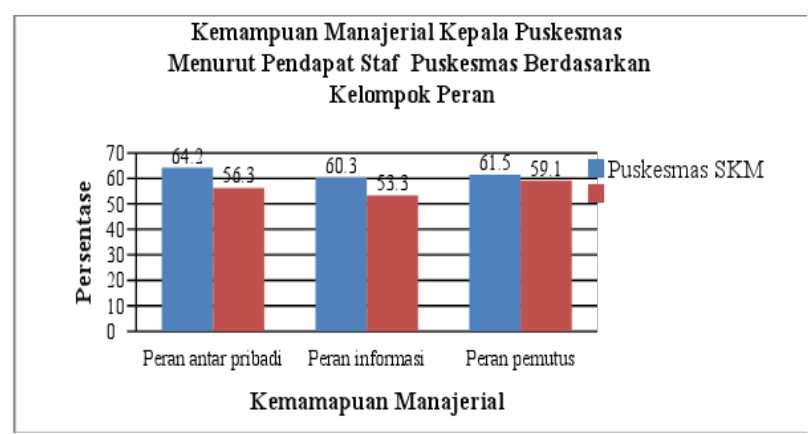

Gambar 2. Kemampuan manajerial kepala puskesmas menurut pendapat staf puskesmas berdasarkan kelompok peran

Gambar 2 menjelaskan kemampuan manajerial menurut pendapat staf puskesmas, diperoleh hasil skor tertinggi kepala puskemas SKM (64,2\%) terdapat pada kelompok peran antar pribadi sedangkan pada kepala puskemas non SKM $(59,1 \%)$ terdapat pada kelompok peran pemutus.

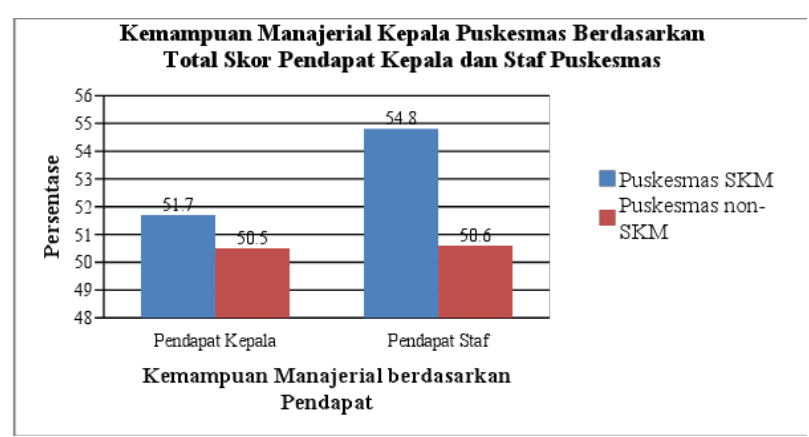

Gambar 3. Kemampuan manajerial kepala puskesmas berdasarkan total skor pendapat kepala dan staf puskesmas

Gambar 3 menunjukkan total skor kemampuan manajerial kepala puskesmas, berdasarkan pendapat kepala dan staf, lebih tinggi pada puskesmas SKM dibandingkan dengan puskesmas non SKM.

Faktor individu memengaruhi kemampuan manajerial. Pengalaman kerja, tidak hanya menyangkut jumlah masa kerja, tetapi lebih memperhitungkan jenis pekerjaan yang pernah atau sering dihadapi. Dari segi penguasaan pekerjaan kepala puskesmas SKM lebih mengetahui kegiatan-kegiatan yang terdapat di puskemas dibandingkan dengan non SKM. hal tersebut terkait dengan masa kerja yang lebih lama.

Masa kerja kepala puskesmas SKM dan non SKM mempunyai pengaruh terhadap kemampuan manajerial. Hal ini dibuktikan dengan pengalaman yang miliki kepala puskesmas selama di puskesmas. Berdasarkan data hasil penelitian kepala puskesmas yang telah mengikuti pelatihan DIKLAT PIM IV, diketahui memiliki kemampuan manajerial lebih baik terutama peran kepemimpinan, dibandingkan dengan yang belum mengikuti pelatihan.

\section{BAHASAN}

Peran antar pribadi. Menurut pendapat kepala dan staf puskesmas, peran pemimpin mempunyai skor tertinggi dalam kelompok peran antar pribadi. Hasil skor $\mathrm{t}$ lebih tinggi pada kepala puskesmas SKM dibandingkan non SKM. Kepemimpinan kepala puskesmas SKM lebih menekankan pada tugas, pokok dan fungsi yang jelas daripada hanya mempercayakan kepada orang yang dipercayainya, sehingga tidak ada kecemburuan sosial antar staf di lingkungan puskesmas tersebut. Hal ini berdampak pada timbulnya iklim kerja yang kondusif antar staf dalam menjalankan segala kegiatan di puskesmas. Pemimpin harus memberi pedoman kepada bawahan, memotivasi, dan menciptakan kondisi kondusif untuk mencapai tujuan organisasi (6). Sifat utama pemimpin dan kepemimpinannya harus sesuai dan harus bisa diterima oleh bawahan serta menciptakan situasi yang kondusif (7).

Kepemimpinan kepala puskesmas SKM menjadikan staf sebagai tim kerja, bukan dianggap bawahan. Saat melakukan kegiatan, kepala puskesmas SKM tidak membuat jarak dalam berinteraksi sehingga suasana lebih terbuka dan penuh keakraban. Hal tersebut dilakukan untuk membangun komunikasi yang baik antara kepala dan staf puskesmas, sehingga diharapkan kinerja yang dihasilkan sesuai dengan tujuan. Kepemimpinan berarti menciptakan budaya dan nilai bersama, mengkomunikasikan tujuan kepada karyawan di seluruh organisasi dan memberikan masukan kepada karyawan agar memiliki kinerja dengan tingkat yang lebih tinggi (8).

Peran informasi. Menurut pendapat kepala dan staf puskesmas, peran penyebar informasi mempunyai skor tertinggi dalam kelompok peran informasi. Hasil skor tersebut lebih tinggi pada kepala puskesmas SKM dibandingkan dengan non SKM. Kepala puskesmas SKM, dalam melakukan peran sebagai penyebar informasi mempunyai waktu yang lebih banyak dibandingkan dengan non SKM. Hal tersebut disebabkan kepala puskesmas SKM tidak mempunyai peran ganda sebagai pemegang jabatan struktural dan fungsional, tetapi hanya berperan sebagai pemegang jabatan struktural, sehingga tidak disibukkan terhadap 
tanggung jawab dengan pasien. Oleh karena itu kepala puskesmas SKM lebih fokus dalam menjalankan kegiatan, baik kegiatan di dalam maupun di luar gedung puskesmas. Pada pelaksanaan kegiatan, peran penyebar informasi terkait dengan peran juru bicara. Pemimpin dalam perannya sebagai juru bicara harus mengomunikasikan informasi kepada orang-orang yang berpengaruh, melakukan pengawasan terhadap organisasi agar berjalan sesuai dengan peraturan sebagaimana mestinya (9). Salah satu faktor untuk menilai berkualitas tidaknya seorang pemimpin dapat dilihat dari aspek peran sebagai juru bicara (10).

Peran pemutus. Berdasarkan hasil wawancara diketahui bahwa peran pengalokasian sumber daya yang dilakukan oleh kepala puskesmas non SKM dalam hal penempatan tugas pegawai. Pada masalah ini kepala puskesmas non SKM lebih tegas, sesuai dengan alokasi yang telah ditetapkan. Hal ini dilatar belakangi hampir sebagian besar kepala puskesmas non SKM bukan penduduk asli atau pendatang di daerah tempat tugasnya, sehingga tidak terkait hubungan pribadi. Kepala puskesmas SKM dalam hal penempatan pegawai lebih bersifat kurang tegas. Hal tersebut dilatar belakangi hampir sebagian besar kepala puskesmas SKM merupakan penduduk asli daerah tempat tugasnya, sehingga lebih banyak mengenal masyarakat di wilayah tersebut. Para pemimpin dituntut untuk meningkatkan kemampuan sumber daya manusia agar dapat lebih efektif dalam melaksanakan tugas dan tanggung jawab sebagai pelaksana administrasi dalam sebuah organisasi (10). Pemimpin harus mampu melakukan seleksi dan menetapkan sasaran dengan mempertimbangkan lingkungan eksternal masa depan yang menjadi tujuan organisasi (11,12,13).

Proses belajar membentuk kepala puskesmas. Berdasarkan hasil kuesioner diketahui bahwa kepala puskesmas SKM di kabupaten OKU Timur semuanya berlatar belakang pendidikan SKM tidak murni, artinya pendidikan yang selama ini ditempuh berjenjang dari pendidikan menengah (SPK), DIII kesehatan kemudian berlanjut ke jenjang S1 kesehatan (SKM). Sedangkan kepala puskesmas non SKM tidak mempunyai latar belakang berjenjang, tetapi langsung ke jenjang pendidikan SI-Kedokteran.

Masa kerja di puskesmas kepala puskesmas SKM sebagian besar diatas 20 tahun, sedangkan kepala puskesmas non SKM paling lama 12 tahun. Dengan melihat masa kerja di puskesmas tersebut sebagian besar kepala puskesmas SKM memiliki masa kerja lebih lama dibanding dengan non SKM. Masa kerja mempunyai hubungan sangat erat dengan pengalaman karena pengalaman dapat memengaruhi keterampilan dan berdampak pada kemampuan seseorang. Keberhasilan pelaksanaan suatu program ditentukan oleh manajer garis depan dengan keterampilan yang lengkap dalam menentukan prioritas, merencanakan, dan memecahkan masalah (14). Sangat dibutuhkan Kepemimpinan yang kuat dan keterampilan manajemen yang efektif untuk melakukan perubahan berkelanjutan dalam skala besar (15).

Seseorang yang berpengalaman akan memiliki kemampuan dalam bekerja sehingga dapat dikatakan bahwa kepala puskesmas yang mempunyai masa kerja di puskesmas lebih lama akan lebih baik dibandingkan dengan kepala puskesmas yang baru saja memasuki dunia kerja. Kapasitas dan kapabilitas kepemimpinan seseorang juga ditentukan oleh seberapa besar pengalaman dan persentuhannya dengan lingkungan bekerja (16). Banyak sedikitnya pengalaman kerja akan menentukan atau menunjukkan bagaimana kualitas dan produktivitas seseorang dalam bekerja (17). Pemimpin yang luar biasa memerlukan tiga kelompok kompetensi sebagai standar kemampuan yang harus dimilikinya, salah satunya adalah keterampilan dan pengalaman (18).

Berdasarkan uraian di atas, dari sudut pandang pengalaman kerja, dapat disimpulkan bahwa proses belajar membentuk kepala puskesmas di kabupaten OKU Timur, yang sesungguhnya bukan berasal dari instansi pendidikan. melainkan pengalaman yang menempa.

Pengalaman memperkuat seseorang untuk berinteraksi sosial. Semua kepala puskesmas SKM di kabupaten OKU Timur mempunyai riwayat pekerjaan sebagai staf puskesmas sebelum menjadi kepala puskesmas. Selain itu masa kerja sebagian besar kepala yang sudah lama, sehingga mempunyai lebih banyak pengalaman dalam memahami masalah sosial di masyarakat. Kondisi tersebut menyebabkan mereka lebih mengenal wilayah kerja, geografis, karakter dan sosial budaya penduduk setempat. Hubungan dengan masyarakat dan lintas sektor sudah terjalin dengan baik, sehingga interaksi sosial sudah terbentuk. Pengalaman dalam kehidupan nyata dapat memperkuat tenaga kerja kesehatan dalam pembangunan kesehatan (21). Sebaliknya kepala puskesmas non SKM tidak melalui staf terlebih dahulu, tetapi sebagian besar langsung menduduki jabatan kepala puskesmas.

Puskesmas di kabupaten OKU Timur sebagian besar berkategori puskesmas pedesaan. Jumlah kepala puskesmas SKM di kabupaten OKU Timur lebih banyak dibandingkan dengan non SKM. Proporsi tenaga 
non-dokter lebih besar di daerah pedesaan dibandingkan dengan tenaga dokter (20). Dengan kondisi demikian, dibutuhkan kepala puskesmas yang mempunyai kepekaan sosial yang tinggi, tanggap dengan permasalahan yang ada, mempunyai jaringan sosial yang kuat disemua lini baik lintas sektor, lintas program maupun masyarakat, dan memahami wilayah kerjanya. Hal tersebut sebagian besar ada pada karakter kepala puskesmas SKM, sehingga lebih memungkinkan untuk menjadi kepala puskesmas. Apabila melihat kebijakan pemerintah kabupaten OKU Timur yang memberikan peluang pada SKM untuk menduduki jabatan sebagai kepala puskesmas, maka kebijakan tersebut sesuai dengan karakter kepala puskesmas yang diharapkan.

Haruskah puskesmas dipimpin oleh non SKM (Dokter)? Peran manajerial yang mempunyai skor lebih tinggi adalah kepala puskesmas SKM, dimana terdapat peran pemimpin, penyebar informasi, penanganan gangguan, dan negosiator. Hasil tersebut menunjukkan bahwa kepala puskesmas SKM lebih banyak melakukan peran manajerial dibandingkan non SKM, baik berdasarkan pendapat kepala dan staf puskesmas. hal ini berkaitan dengan rendahnya kemampuan dokter yang baru lulus dalam bidang manajemen kesehatan masyarakat. Kemampuannya akan meningkat seiring dengan waktu karena adanya pelatihan dan aktualisasi hasil pelatihan yang diterapkan dalam praktek sehari-hari (21). Pelatihan kepemimpinan bagi mahasiswa kedokteran sangat terbatas, lebih menekankan pada pelatihan klinis. Kondisi tersebut mengakibatkan setelah menjadi pimpinan di pelayanan primer, lebih berfokus pada aspek klinis sebagai tanggung jawab utama (22). Pelatihan yang diperoleh lebih efektif dan efisien dalam meningkatkan sumber daya kesehatan (23).

Kelebihan kepala puskesmas SKM dibandingkan non SKM dalam meningkatkan kemampuan manajerial puskesmas adalah : 1) lebih fokus dalam melaksanakan setiap kegiatan di dalam dan luar gedung; 2) memiliki team work yang kuat antara pimpinan dan staf karena didasari sifat keterbukaan; 3) mempunyai social network yang baik antara pimpinan, lintas program dan lintas sektor; dan 4) memiliki pengalaman yang lebih banyak terkait dengan lamanya masa kerja di puskesmas.

\section{SIMPULAN}

Kelebihan kepala puskesmas SKM dibandingkan dengan non SKM maka puskesmas tidak harus dipimpin oleh seorang kepala puskesmas non SKM (dokter) tetapi kepala puskesmas SKM mampu untuk memimpin puskesmas. Tidak ada perbedaan kemampuan manajerial antara kepala puskesmas SKM dan non SKM.

Dinas Kesehatan kabupaten OKU Timur dalam pengusulan pengangkatan kepala puskemas SKM perlu memperhatikan kompetensi dan pelatihan jabatan struktural kepala puskesmas. Kepala puskesmas nonSKM (dokter) disarankan agar tidak menerapkan kebijakan rangkap jabatan dan bagi kepala puskesmas SKM seharusnya dapat menggunakan kewenangan dan otoritas yang dimili.

\section{Abstrak}

Tujuan: Penelitian ini bertujuan untuk mengetahui kemampuan manajerial kepala puskesmas SKM dan non SKM berdasarkan 10 peran manajerial. Metode: Merupakan jenis penelitian deskriptif dengan rancangan studi kasus, menggu- nakan metode kualitatif yang didukung dengan data kuantitatif. Sampel penelitian sebanyak 8 orang terdiri dari 4 orang kepala puskesmas SKM dan 4 orang kepala puskesmas non SKM. Staf yang menjadi informan untuk dimintai pendapat tentang kemampuan manajerial pimpinanya sebanyak 40 orang dan 1 orang pejabat dinas kesehatan. Pengambilan sampel dilakukan secara purposive sampling. Metode pengumpulan data diperoleh melalui wawancara mendalam dan kuesioner. Hasil: Pengalaman kerja yang dimiliki kepala puskesmas SKM lebih banyak dibandingkan dengan non SKM. Masa kerja di puskesmas mempunyai pengaruh terhadap kemampuan. manajerial. Sebalik- nya tidak ada perbedaan masa kerja menduduki jabatan kepala puskesmas antara yang paling lama dengan yang paling sedikit terhadap kemampuan manajerial. Kepala puskesmas yang telah mengikuti pelatihan DIKLAT PIM 1V dan pelatihan jabatan struktural lainnya diketahui memiliki kemampuan manajerial lebih baik pada peran kepemimpinan dibanding dengan yang belum mengikuti pelatihan. Simpulan: Tidak ada perbedaan kemampuan mana- jerial antara kepala puskesmas SKM dan non SKM.

Kata kunci: peran; kepala puskesmas; kemampuan manajerial 


\section{PUSTAKA}

1. Departemen Kesehatan. Keputusan Menteri Kesehatan Republik Indonesia Nomor 128/Menkes/SK/II/2004 tentang Kebijakan Dasar Puskesmas. Jakarta: 2004.

2. Dinas Kesehatan Oku Timur. Profil Kesehatan Kabupaten OKU Timur Tahun 2014.

3. Mintzberg, H. The Structuring Of Organization. ENgelword Clifits. NJ Prentice Hall; 1979.

4. Gibson, JL, Ivancevich, JM, Donelly, JJ. Organisasi Perilaku, Struktur, Proses. Jakarta: Bina Rupa Aksara. 1996.

5. Sutermeister, RA. People and Productivity. Toronto, Mc.Graow Hill. 1999.

6. Yukl, G. Kepemimpinan dalam organisasi. Jakarta: PT Indexs. 2009.

7. Kartono, K. Pemimpin dan Kepemimpinan, Jakarta: PT Cipta Rineka. 2005.

8. Daft, RL. Kepemimpinan dalam manajemen, Jakarta: PT Raja Grafindo Persada. 2007.

9. Dewi, TS. Peranan Komunikasi dalam Organisasi. 2013.

10. Bennis, W, Nanus, B. Leaders Strategi untuk Mengemban Tanggung Jawab, Jakarta: PT Buana Ilmu Populer Kelompok Gramedia. 2006.

11. Nanus, B, Dobbs, SM. Leaders Make Different Strategies for Meeting the Non Profit Challenge, San Francisco: Jossey bass. 2001.

12. Komariah, A. Visionary Leadership: Menuju Sekolah Efektif, Jakarta: Bumi Aksara. 2008.

13. Sujatno, AM. Traktat Etis Kepemimpinan Nasional, Jakarta: Wahana Semesta Intermedia. 2008.

14. McEwan, E, Conway, MJ, Bull, DL, Malison D. Developing Public Health Management Training Capacity in Nicaragua. American Journal of Public Health, 2001:911586-1588.
15. Rowe LA, Brillant SB, Cleveland E, Dahn BT, Ramanadhan S, Podesta M, Bradley EH. Building capacity in health facility management: guiding principles for skills transfer in Liberia. Human Resources for Health. 2010 Dec;8(1):5.

16. Pamudji, S. Kepemimpinan Pemerintahan Indonesia, Jakarta: Bina Aksara. 2010.

17. Muhibbin, Syah. Psikologi Pendidikan Suatu Pendekatan Baru. Bandung: PT. Remaja Rosdakarya. 1995.

18. Boyatzis, RE. Managerial and Leadership Competencies A Behavioral Approach to Emotional, Social and Cognitive Intelligence. Vision: The Journal of Business Perspective, 2011;15(2), 91-100.

19. Matovu, JK, Wanyenze, RK, Mawemuko, S, Okui, O, Bazeyo, W, Serwadda, D. Strengthening health workforce capacity through work-based training. BMC international health and human rights, 2013;13(1), 8.

20. Grumbach K, Hart LG, Mertz E, Coffman J, Palazzo L. Who is caring for the underserved? A comparison of primary care physicians and nonphysician clinicians in California and Washington. The Annals of Family Medicine. 2003 Jul 1;1(2):97-104.

21. Adisasmito W, Purwantyastuti P, Djuwita R, Thabrany $\mathrm{H}$, Iljanto S, Kamso S, Vidiawati D. Stakeholders' Perception About Medical Doctors' Competency in Primary Health Care. Journal of the Indonesian Medical Association. 2011 Aug 17;60(01).

22. Hana J, Kirkhaug R. Physicians' leadership styles in rural primary medical care: How are they perceived by staff?. Scandinavian journal of primary health care. 2014 Mar 1;32(1):4-10.

23. Gaye PA, Nelson D. Effective scale-up: avoiding the same old traps. Human Resources for Health. 2009 Dec;7(1):2. 
Berita Kedokteran Masyarakat, Volume 32 No. 9 Tahun 2016 